\title{
Shift work problems of healthcare workers at Kerman University of Medical Sciences, Iran, 2013
}

\author{
Rahimi-Moghadam S, MSc ${ }^{1,2}$, Khanjani N, $\mathrm{PhD}^{3}$, Feyzi V, MSc ${ }^{4 *}$, Naderi M, BSc ${ }^{5}$, Sadeghi \\ H, PhD Student ${ }^{6}$
}

1- MSc in Occupational Health Engineering, Dept. of Occupational Health Engineering, Nyshabur University of Medical Sciences School of Medicine, Nyshabur, Iran. 2- Student Research Committee, Health Sciences Research Centre, Mazandaran University of Medical Sciences, Sari, Iran. 3- Associate Prof., Environmental Health Engineering Research Center, Kerman University of Medical Sciences, Kerman, Iran. 4- MSc in Occupational Health, Dept. of Occupational Health, Health Center of Saghez, Kurdistan University of Medical Sciences, Sanandaj, Iran. 5- BSc in Occupational Health, Dept. of Occupational Health Engineering, Kerman Medical Science University, Kerman, Iran. 6- PhD Student, Dept. of Nursing, Student Research Committe, University of Social Walfare and Rehabilitation Sciences, Tehran, Iran.

\begin{abstract}
Received: August 2017, Accepted: December 2017

Background: Shift work can cause problems for workers' health, especially nurses. This study was done to assess the problems caused by shift work and the nature of the job in nurses of the educational hospitals of Kerman University of Medical Sciences, Iran.

Materials and Methods: This was a descriptive study carried out in 2013. The research participants were 159 nurses with and without shift work and 167 employees from one of the hospitals affiliated to Kerman University of Medical Sciences. Data were gathered via the survey of shift workers (SOS) questionnaire and were analyzed by SPSS software.

Results: There were $41.1 \%(n=134)$ shift working nurses, $7.7 \%(n=25)$ fixed daytime nurses and $51.2 \%(\mathrm{n}=167)$ fixed daytime employees. Their average age was $35.7 \pm 6.4,34.0 \pm 6.9$ and $40.0 \pm$ 6.8 , respectively. This study showed that headache and dizziness $(\mathrm{P}=0.001)$, lack of concentration $(\mathrm{P}$ $=0.011)$, boredom $(\mathrm{P}=0.001)$, depression $(\mathrm{P}=0.001)$, irritability $(\mathrm{P}=0.001)$ and fatigue during the day $(\mathrm{P}=0.026)$ were significantly higher among shift workers. Shift work significantly affected the personal $(\mathrm{P}=0.029)$, family $(\mathrm{P}=0.039)$ and social life $(\mathrm{P}=0.001)$ of the shift working nurses, and also caused more musculoskeletal and psychosocial disorders.

Conclusions: Shift work may cause musculoskeletal and psychological problems and have a negative impact on nurses' personal, family and social life. Allowing nurses to choose shift work based on their own will, and the regular rotation of shifts can decrease the problems arising from shift work.
\end{abstract}

Keywords: Shift Work, Healthcare Workers, Health Problems, Iran

\section{Introduction}

Occupational environments, either industrial or non-industrial, expose their employees to hazardous factors such as noise, vibration, chemicals, and shift work (1-4). The high prevalence of shift work in societies is due to factors such as the necessity of providing 24hour services, continuous industrial processing, and increased income. Shift work is usually done in the morning, afternoon and night shifts. These shifts are also named as day shift, suspended shift and graveyard shift (5). The reason for graveyard appellation to night shift is its incompatibility with human physiology and its unfavorability among workers. Previous studies have shown that people are more inclined to work during the day and sleep at night (6).

The number of people working in shifts has increased in the last decade. About $15 \%$ of workers in the USA and $20 \%$ in Europe do shift work (7). Due to its necessity, different social and industrial services are forced to provide 24-hour services and use their human

\footnotetext{
* Corresponding author: Vafa Feyzi, Dept. of Occupational Health, Health Center of Saghez, Kurdistan University of Medical Sciences, Sanandaj, Iran. E-mail: vafa.faizi@yahoo.com
} 
resources and facilities 24 hours a day. Nursing services are one of the jobs that have to be done in shift work and this can cause a disturbance in the biological rhythm which can lead to physiological disorders and make nurses prone to physical, mental and social problems $(7,8)$. Studies have shown that working in shifts can cause problems in social communications and family life as well $(7,9)$.

Research has shown that more than one third (43.3\%) of Iranian nurses are not happy with their jobs (8). A study conducted by Choobineh et al. on workers of the petrochemical industry showed that the prevalence of gastrointestinal and psychological problems in shift workers is significantly more than day workers (10). In another study, a significant association was found between working in night shifts and abusing alcohol (11), decreased sleeping quality and drowsiness during the day (12).

The results of previous studies have shown that the prevalence of health problems was higher among shift work operating-room technicians. The prevalence of psychological and gastrointestinal problems and adverse social effects were $97.6 \%, 70.6 \%$, and $66.5 \%$ among shift workers, respectively (9). Increased epidemiology and clinical research about shift work have shown more negative effects of this risk factor on human health in both social and psychosocial dimensions. These wide range problems vary from changes in the circadian rhythm and sleep-wakening cycle to psychosomatic problems. Shift work also can increase the incidence of cancer and can have negative effects on family and social life (13). Many studies have shown that gastrointestinal disease is higher among shift workers than day workers (14).

It seems that irregular working hours has dramatic effects on sleep and vigilance during the morning and night shifts. These work shiftrelated disorders are similar to clinical insomnia and can cause huge human and financial losses, because they increase accidents and frustration, and decrease productivity. However, some authors have not found an association between irregular working hours and chronic insomnia (15).

Studies have reported that women working during night shifts are less fertile and are more likely to experience miscarriages in comparison to day working nurses. The reason is not only hormonal disorders related to shift work, but also because many shift workers prefer not to have babies, because of their occupational and organizational commitments. Irregular shift work affects family commitment as well (13).

Nurses and midwives are important groups in providing the medical services with high quality, and therefore, the psychosomatic health of staffs is crucially important. This study discusses some problems related to shift work among nurses working in the educational hospitals of Kerman University of Medical Sciences, Kerman, Iran.

\section{Materials and Methods}

This was a cross-sectional study carried out in 2013. The study population consisted of 159 nurses working at the Afzalipoor Educational Hospital, Kerman, in shift work or day work, and 167 day working employees of Kerman University of Medical Sciences.

The project was approved by the Kerman Medical University Ethics Committee (No. 90/95- 2011). Permission was obtained from the hospital and the university managers.

The project was explained to all eligible employees and people volunteered to participate. People were eligible to participate if they had at least one-year work experience, didn't have a second job, and consented to participate. The aim of this study was thoroughly explained to the participants and they were assured that their information would remain confidential. Informed consent was obtained from the participants. Data collection was done at the participants' workplace during their free time.

Data were collected via the survey of shift workers (SOS) questionnaire. This questionnaire was developed by the shift work 
research team of Medical Research Council/ Economic and Social Research Council (MRC/ESRC) Social and Applied Psychology Unit in UK (16). This questionnaire has been validated in the Persian language and the Cronbach's alpha was 0.81 . The validity of the questionnaire and its scales were 0.21 and 0.71 (17). Besides demographical information (age, sex, marital status, work experience, education), this questionnaire asked about shift work history, shift work rotations, their sleeping schedule, sleeping hours, insomnia, the use of sleeping medication, mental disorders, job satisfaction, gastrointestinal, musculoskeletal and cardiovascular problems. It also asked about the negative effects of shift work on workers individual activities (rest, reading, physical activity, going to the bank) as well as their family (not having enough time for doing household work, attending the kids, seeing parents, participating in family activities) and social life (participating in social functions, parties, religious ceremonies and sports events).

This questionnaire included 57 questions in which the first 11 questions were about demographic information and the rest of the questions were about sleep disorders, happiness in the person's private life, satisfaction in the family and social life, mental, cardiovascular, gastrointestinal and musculoskeletal disorders. The questions of each part were separate. There were 13 questions in the questionnaire which had been specially designed for only shift working people and not non-shift working employees. Therefore, people not exposed to shift work only answered 44 questions. The question scores were based on a Likert scale.

In this research, daytime nurses, shift working nurses and day shift employees completed the questionnaire. The collected data were analyzed by SPSS software (version 18, SPSS Inc., Chicago, IL, USA). Descriptive statistics were reported. The chi-square test was used to examine the differences in the frequency of mental health, gastrointestinal, and musculoskeletal disorders and the impact of shift work on the individuals, family and social activities of employees. Analysis of variance (ANOVA) was used to determine the difference in age, experience and hours of sleep between the groups. The level of significance was $<0.05$.

\section{Results}

In this study, 326 people participated, in which $134(41.1 \%)$ were shift working nurses with an average age of $34.0 \pm 6.9,25(7.7 \%)$ were fixed daytime workers with an average age of $35.7 \pm 6.4$, and 167 (51.2\%) were office employees of Kerman University of Medical Sciences with an average age of $40.0 \pm 6.8$. $81.3 \%$ were women, $23.4 \%$ were single, $73.3 \%$ were married, $2.5 \%$ were divorced and $0.6 \%$ were widowed. $12 \%$ had a high school diploma, $8.3 \%$ had a graduate diploma, $71.3 \%$ had bachelor, and $8.6 \%$ had master's degrees. The demographic information can be seen in our previous publication (12).

Table 1 showed the answers of shift working nurses to questions related to shift work. In $61.9 \%$ of the cases the direction of shift working was irregular and contrary to the clockwise direction, and in $52 \%$ of cases, the organization's force was the reason of employment in shift work. 69 nurses $(51.5 \%)$ had less than 6 hours of sleep in 24 hours. The family support of night workers in providing the condition for a comfortable sleep and proper nutrition was medium to high in 96 nurses $(71.6 \%)$. In over $90 \%$ of the shift working nurses, there was a possibility to rest and take a nap in the break room, but they expressed dissatisfaction about their sleep quality. 
Table 1: The answers of shift working nurses (SN) to variables related to shift working (Kerman 2013)

\begin{tabular}{|c|c|c|}
\hline \multicolumn{2}{|r|}{ Variable } & Answer frequency $(\%)$ \\
\hline \multirow{2}{*}{$\begin{array}{c}\text { The direction of shift } \\
\text { work plan }\end{array}$} & Regular and clockwise & $51(38.10)$ \\
\hline & Irregular and anticlockwise & $83(61.90)$ \\
\hline \multirow{4}{*}{$\begin{array}{l}\text { Sleep hours after the night } \\
\text { shift }\end{array}$} & Less than 6 hours & $69(51.50)$ \\
\hline & 6-7 hours & $43(32.10)$ \\
\hline & $8-10$ hours & $19(14.20)$ \\
\hline & More than 10 hours & $31(2.20)$ \\
\hline \multirow{4}{*}{$\begin{array}{l}\text { Family support of the shift } \\
\text { working nurse }\end{array}$} & Never & $18(13.40)$ \\
\hline & A little & $20(14.90)$ \\
\hline & Average & $70(52.20)$ \\
\hline & A lot & $26(19.40)$ \\
\hline \multirow{4}{*}{$\begin{array}{l}\text { Probability of sleeping in } \\
\text { a night shift }\end{array}$} & No & $10(7.50)$ \\
\hline & Less than a 1:30 hour & $13(9.70)$ \\
\hline & 1.30 to 2.30 hours & $49(36.60)$ \\
\hline & More than 2.30 hours & $62(46.30)$ \\
\hline \multirow{5}{*}{$\begin{array}{c}\text { Reasons for choosing } \\
\text { night shift }\end{array}$} & Organizational obligation & $70(52)$ \\
\hline & $\begin{array}{l}\text { Career interest, economic reasons, } \\
\text { dealing with house chores on the next } \\
\text { day, easier tasks during night shifts }\end{array}$ & 13(9) \\
\hline & Shortage of Employees & $21(15.70)$ \\
\hline & Blank answer & $31(23.10)$ \\
\hline & Total score & $134(100)$ \\
\hline
\end{tabular}

The results also showed that only 13 nurses (9\%) had chosen shift work voluntarily, because of their own interest, having a second job, having more off days and being on-call. The relation between voluntarily choosing the job and job satisfaction was significant $(\mathrm{P}=$ 0.041), and those who had chosen the job voluntarily were more satisfied. Also, there was a significant association between job rotation and job satisfaction $(\mathrm{P}=0.036)$, and those who had regular rotations were more satisfied.

The results showed that shift work had a significant effect on the individual activities ( $P$ $=0.029)$, family life $(\mathrm{P}=0.039)$ and social life $(\mathrm{P}=0.001)$ of the shift-working nurses in comparison to the permanent daytime nurses. Compared to permanent daytime nurses, the shift working nurses had less concentration $(\mathrm{P}$ $=0.040$ ) during their work time and also felt less confident $(\mathrm{P}=0.001)$. But with respect to decisiveness, no significant difference was observed between the daytime and shift nurses $(\mathrm{P}=0.490)$.
According to the results, the shift nurses significantly suffered from insomnia in comparison with their daytime co-workers $(\mathrm{P}$ $=0.009)$. However, no noticeable difference was observed with respect to using sleeping medication $(\mathrm{P}=0.050)$. Comparison between the shift nurses and the daytime employees indicated that there was a significant difference between the two groups in terms of using sleeping medication $(P=0.001)$. Shift nurses used such medication more frequently, but shift working nurses and daytime nurses were the same in using sleeping drugs. Shift working nurses also suffered from insomnia more than the daytime employees $(\mathrm{P}=0.001)$. No significant difference was observed between the daytime nurses and the shift working nurses in regard to cardiovascular problems $(\mathrm{P}=0.050)$.

The results of table 2 show that shift work has adverse effects on nurses' personal, societal and family life. Also, psychological and musculoskeletal disorders were high among this group. 
Table 2: The prevalence of disorders among shift working nurses (Kerman, Iran, 2013)

\begin{tabular}{cc}
\hline Disorder & Frequency (\%) \\
\hline Mental disorder & $69(56.7)$ \\
\hline Musculoskeletal disorders & $124(92.55)$ \\
\hline Cardiovascular problems & $17(12.70)$ \\
\hline Adverse effect on personal life & $133(99.30)$ \\
\hline Adverse effect of family life & $133(99.30)$ \\
\hline Adverse effect on social life & $134(100)$ \\
\hline
\end{tabular}

This study showed that in regard to a headache and dizziness, lack of concentration, boredom, depression, irritability, and fatigue during the day, there was a significant difference between shift working nurses and daytime workers (daytime nurses and daytime staff of the university) (Table 3).

Table 3: The odds ratio of mental problems comparing shift work nurses to fixed daytime nurses and university staff (Kerman, Iran, 2013)

\begin{tabular}{ccc}
\hline Mental problem & OR $(\mathbf{9 5 \%} \mathbf{C I})$ & $\mathbf{P}^{*}$ \\
\hline Headache and dizziness & $1.54(1.09-3.09)$ & 0.0001 \\
\hline Anger & $1.27(0.77-2.10)$ & 0.341 \\
\hline Lack of concentration & $2.88(1.20-6.91)$ & 0.011 \\
\hline The number of mistakes & $1.07(0.35-3.26)$ & 0.901 \\
\hline Boredom & $2.19(1.35-3.55)$ & 0.001 \\
\hline Depression & $4.32(2.22-8.40)$ & 0.0001 \\
\hline Irritability & $2.92(1.49-5.70)$ & 0.001 \\
\hline Fatigue during the day & $1.68(1.06-2.67)$ & 0.026 \\
\hline * Chi-square test & & \\
OR: Odds ratio; CI: Confidence interval & &
\end{tabular}

\section{Discussion}

Nursing is one of the jobs that require shift work. Many employees in this profession do not have the ability to adapt to shift work and confront many health problems and disorders. Our study showed that psychosocial problems were more prevalent among shift workers.

In this study, the most and the least frequent reason to work as a shift working nurse was an organizational obligation and personal interest with $52 \%$ and $9 \%$ frequency, respectively. The results of this study are consistent with the result of Beers et al. that most people were engaged in shift work, due to the obligation of their working system and fear of unemployment in California (18). Choobineh et al. showed that those workers who choose shift work voluntarily are more satisfied with their job compared to those who are obliged to choose it (9). Studies have shown that only
$10 \%$ of workers enjoy shift work, and the rest only compromise with it (11).

In respect to the direction of shift work rotations, $61.9 \%$ of our participants had an irregular, anticlockwise schedule. Choobineh et al. also found that $73.5 \%$ of their participant had the same irregular rotations (9). The shift work rotation should be clockwise with morning, afternoon and night shifts direction, which is called as the progressive system. The opposite direction is the regressive shift system where the rotation direction is night, afternoon and morning shifts, respectively, and is anticlockwise. Studies have proved that progressive systems are more suitable and tolerable, ultimately leading to more efficiency, comfort, and sleep quality as well as the resolution of physical, mental and social problems (17). The findings also have shown that shifts should change weekly (not sooner) or even after 3-4 weeks in a clockwise 
direction and those workers whose shift rotated in less than a week experienced more work-related incidents, less efficiency, insomnia, digestive disorders, mental fatigue, and depression as well as mental and physical illnesses. Despite all of the existing evidence, shift rotation for many workers happens weekly and is anticlockwise (19).

The results of this study showed that some psychological problems such as a headache and dizziness, lack of concentration, boredom, depression, irritability, and fatigue during the day were more frequent as well.

Shift work has many adverse chronic health effects. Studies have shown that chronic psychological, cardiovascular and gastrointestinal problems happened more frequently in shift working employees (20). The results of Choobineh et al. about the health problems of operating room technician in Shiraz, Iran, showed that the prevalence of psychological $(97.6 \%)$ and gastrointestinal disorders $(70.6 \%)$ was higher in shift working technicians (9). In the study done by Asghari et al. about the health complications of shift working among automobile industry workers, $82 \%$ reported at least one gastrointestinal symptom and this symptom was more likely to be a loss of appetite, stomach pain or dyspepsia (21). Rutenfranz et al. reported that shift work undoubtedly has adverse effects on the gastrointestinal system and these effects are a loss or increased appetite, diarrhea, constipation, gastrointestinal sores or chronic dyspepsia. The prevalence of these disorders was so high, that almost all shift working employees reported gastrointestinal symptoms (22). In another study by Esquirol et al. about rotating shift work and metabolic syndrome in 2009, shift work was shown to cause occupational stress and increased risk of gastrointestinal problems (23).

Studies have shown that shift working causes increased problems including psychosomatic and gastrointestinal disorders, nervousness, dilution, aggressiveness, social problems, emotional illness and lack of concentration among healthcare workers (24). These results are in line with the results of our study. The effect of shift working in increasing these disorders among different job group employees and the similarity of the results may be due to similarities in shift working hours and the employment situation in the occupational environments under study. This high prevalence is probably related to the incompatibility of shift work with the circadian cycle and long 12-hour working shifts and inappropriate working conditions (17).

Another finding of this research was a significant relationship between job satisfaction. Shift work and non-shift nurses were more satisfied with their career in comparison with shift working nurses. Results also proved that shift working nurses with a regular shift rotation had more job satisfaction compared to the nurses with irregular shift rotations. However, the difference was not significant.

The results of this study showed that musculoskeletal disorders were high among shift workers (92.5\%). Choobineh et al. also showed that the odds ratio of musculoskeletal disorders were 1.93 times more in shiftworkers in comparison to day workers (9). Also, different studies have shown that the prevalence of stress, occupation tension, and musculoskeletal disorders, which are probably one the consequences of occupational stress, was higher among healthcare workers especially nurses and midwives (2, 25-27). The reason is probably encountering severely ill patients, environmental noise, and moving patients.

Choobineh et al. showed that shift work causes various disorders and decreases job satisfaction (9). However, people who work in shifts and have chosen it voluntarily, have more job satisfaction in comparison with people who have accepted it compulsorily. Therefore, choosing volunteers for shift work can increase job satisfaction, and furthermore, can increase motivation which itself has an important effect on efficiency and productivity (28). Other studies have also shown that 
people who have chosen shift work compulsorily are not satisfied with their job and take more leaves from the job. One of the other adverse effects of job satisfaction is job quitting.

Proper decisions about the shift work schedule which are based on ergonomic principles, and suitable healthcare and social support are among the preventive factors for later complications (29). It is also noteworthy to know that decreasing night-work hour, having a chance to sleep during night shifts, using fresh food and employing early risers and young workers can reduce shift work-related problems (15). Establishing correct patterns, considering the nature of the job and its suitability with the person's potentials, paying proper wages, acknowledging the value of different shift works, improving the quality of shift works and spreading the sense of empathy leads to increased efficiency and the prevention of physical and mental problems.

One of the limitations of this study was the low cooperation of the employees, because of time restraints and limited resources. Also, the adverse health effects reported in this study were probably not solely related to shift work and other factors were involved as well. Therefore, all different aspects of the job and their employees should be considered in order to decrease health problems among nurses. Conducting more research on various factors such as individual differences and diet, and working details among different populations and with bigger sample sizes are highly recommended.

\section{Conclusion}

This study showed that problems such as personal, social and family, and mental problems are more prevalent among shift working nurses. Managers and nurses should become aware of shift work problems and find the solutions in order to maintain their employees' health more efficiently and to prevent job-related and non-job-related mistakes which are caused by shift work problems such as insomnia, fatigue and lack of concentration.

\section{Acknowledgments}

The authors would like to thank of Akram Sadat Jafari-Roodbandi, Somayeh Daneshvar, Maryam Jalali and all of the hospital and university managers who allowed us to conduct our study, and the nurses and employees who participated in this study. This study was supported by Kerman University of Medical Sciences. Grant No: 90/95- 2011.

Conflict of interest: None declared.

\section{References}

1. Ghotbi MR, Khanjani N, Barkhordari A, Rahimi Moghadam S, Mozaffari A, Gozashti $\mathrm{MH}$. Changes in urinary catecholamines in response to noise exposure in workers at Sarcheshmeh Copper Complex, Kerman, Iran. Environ Monit Assess 2013; 185(11):8809-14.

2. Mohammadian M, Hashemi Nejad N, Rahimi Moghadam S, Amiri F. The survey of musculoskeletal disorders of midwives and its relationship with job stress. Journal of Fundamentals of Mental Health 2013; 15(59):171-83.

3. Hashemi Nejad N, Emkani M, Rahimi Moghadam S, Sadeghi N, Firoozi Chahak A. Exposure to vibration and Its relationship with the low-back pain in the drivers of mining heavy vehicles. International Journal of Occupational Hygiene 2017; 9(2):93-8.

4. Rahimi Moghadam S, Khanjani N. Evaluation of hearing loss and changes in blood pressure of welders in a 4 Year period. International Journal of Occupational Hygiene 2013; 5(4):172-6.

5. Helander M. The Ergonomics of Manufacturing. [AR. Choobineh, trans] $2^{\text {nd }}$ ed. Shiraz: Tacher Publication; 2001. P.309-16.

6. Moonk T, Folkard S. Shiftwork, problems and solutions. [AR. Choobineh, trans]. $3^{\text {rd }}$ ed. Shiraz: Shiraz University of Medical Sciences Publication; 2005. P.1-4.

7. Fialho G, Cavichio L, Povoa R, Pimenta J. Effects of 24-h shift work in the emergency room on ambulatory blood pressure monitoring values of medical residents. Am J Hypertens 2006; 19(10):1005-9.

8. Mahdizadeh SM. Assessing the level of serum Cortisol and Aldestrone of nursing personal in various work shifts in Mashhad medical 
sciences hospitals. Iran Occupational Health 2009; 6(1):56-60.

9. Choobineh A, Shahcheragh B, Keshavarzi S, Rahnama K. Shift work-related problems among operation room technicians of Shiraz University of Medical Sciences hospitals, 2006-2007. Iran Occupational Health 2007; $4(1): 48-52$.

10. Choobineh A, Soltanzadeh A, Tabatabaee SHR, Jahangiri M, Khavaji S. Shift workrelated health problems in "12-hour shift" schedule in petrochemical industries. Iran Occupational Health 2010; 7(1):44-53.

11. Ohida T, Kamal A, Sone T, Ishii T, Uchiyama M, Minowa M, et al. Night-shift work related problems in young female nurses in Japan. $\mathrm{J}$ Occup Health 2001; 43(3):150-6.

12. Jafari Roodbandi AS, Feyzi V, Khanjani N, Rahimi Moghadam S, Shafizadeh Bafghi M, Moghadasi $M$, et al. Sleep quality and sleepiness: a comparison between nurses with and without shift work, and university employees. International Journal of Occupational Hygiene 2017; 8(4):230-6.

13. Costa G. Shift work and health: current problems and preventive actions. Saf Health Work 2010; 1(2):112-23.

14. Reynolds AC, Paterson JL, Ferguson SA, Stanley D, Wright KP Jr, Dawson D. The shift work and health research agenda: considering changes in gut microbiota as a pathway linking shift work, sleep loss and circadian misalignment, and metabolic disease. Sleep Med Rev 2017; 34:3-9.

15. Akerstedt T. Shift work and disturbed sleep/wakefulness. Occup Med (Lond) 2003; 53(2):89-94.

16. Barton J, Spelten E, Totterdell P, Smith L, Folkard S, Costa G. The Standard Shiftwork Index: a battery of questionnaires for assessing shiftwork-related problems. Work Stress 1995; 9(1):4-30

17. Choobineh A, Rajaeefard A, Neghab M. Problems related to shiftwork for health care workers at Shiraz University of Medical Sciences. East Mediterr Health J 2006; 12(34):340-6.

18. Beers TM. Flexible schedules and shift work: replacing the '9-to-5' workday?. Monthly Labor Review 2000; 123(6):33-40.

19. Shields M. Shift work and health. Health Rep
2002; 13(4):11-33.

20. Garbarino S. Shiftwork. Impact on health and safety in the working environment. G Ital Med Lav Ergon 2006; 28(1):89-105.

21. Asghari M, Ahmadnezhad I, Rahmani AR, Sadeghi A, Abbassinia M, Rezaei E, et al. Investigation of disorders and problems caused by shift work in an automotive industry. Journal of North Khorasan Universityof Medical Siencece 2013; 5(1):7-14.

22. Rutenfranz J, Colquhoun WP, Knauth P, Ghata JN. Biomedical and psychosocial aspects of shift work. A review. Scand J Work Environ Health 1977: 3(4):165-82.

23. Esquirol Y, Bongard V, Mabile L, Jonnier B, Soulat JM, Perret B. Shift work and metabolic syndrome: respective impacts of job strain, physical activity, and dietary rhythms. Chronobiol Int 2009; 26(3):544-59.

24. Muecke S. Effects of rotating night shifts: literature review. J Adv Nurs 2005; 50(4):4339.

25. Hashemi Nejad N, Rahimi Moghadam S, Mohammadian M, Amiri F. Survey of relationship between mental health and job stress among midwives who were working in hospitals of Kerman, Iran, 2011. Iranian Journal of Obstetrics, Gynecology and Infertility 2013; 16(64):1-9.

26. Rahimi Moghadam S, Emkani M, Mohamadyan M, Moosazadeh M, Khanjani N, Layegh MN, et al. Musculoskeletal disorders and its relation with job stress in midwives. International Journal of Occupational Hygiene 2017; 9(1):38-45.

27. Rahimi Moghadam S, Moosazadeh $M$, Mohammadyan M, Emkani M, Khanjani N, Layegh Tizabi MN. Psychological health and its relation with occupational stress in midwives. International Journal of Occupational Hygiene 2017; 8(4):217-22.

28. Bohle Ph, Quinlan M, Kennedy D, Williamson A. Working hours, work-life conflict and health in precarious and "permanent" employment. Rev Saude Publica 2004; 38(Supl):19-25.

29. Caruso CC, Lusk SL, Gillespie BW. Relationship of work schedules to gastrointestinal diagnoses, symptoms, and medication use in auto factory workers. Am J Ind Med 2004; 46(6):586-98. 